\title{
Role of Magnetic Resonance Imaging in Diagnosis of Abnormal Placentation
}

\author{
HANY M.A. SEIF, M.D.*; HAZEM A. YOUSEF, M.D.*; ESAM EL-DIN R. ABD AL-HAFEEZ, M.D.** and \\ AL-SHAIMAA A. AL-SAYED, M.Sc.* \\ The Departments of Diagnostic Radiology* and Obstetrics \& Gynecology**, Faculty of Medicine, Assiut University, Egypt
}

\begin{abstract}
Background: To highlighten the role of Magnetic Resonance Imaging (MRI) in detecting abnormal placentation.

Aim of Study: To determine the role of MRI in diagnosis of abnormal placentation comparing the results with postoperative and/or histopathological results.

Patient and Methods: Thirty three females patient were referred to MRI Unit with suspected placenta accreta by transabdominal ultrasound or showed inconclusive findings. MRI was done and the MRI diagnosis was compared to post partum findings and histopathological result.

Results: Twenty three patients $(69.7 \%)$ had MRI diagnosis of abnormal placentation, 15 cases were diagnosed as placenta accreta and increta (45\%), seven cases diagnosed as placenta percreta $(21.2 \%)$, while ten cases $(30.3 \%)$ were placenta previa without accreta. One case diagnosed as ectopic pregnancy $(3 \%)$. Twenty one cases proved to have placental invasion either intra operative finding and/or by histopathological data, 13 cases (3 9.4\%) had placenta accreta and increta, 7 cases $(21.2 \%)$ had placenta percreta $(21.2 \%) \&$ one ectopic on CS scar (3\%).
\end{abstract}

MRI shows sensitivity and specificity of $100 \% \& 83.33 \%$ respectively.

Conclusion: Magnetic resonance imaging hand in hand with ultrasound is important for the accurate diagnosis of abnormal placentation. Co-operation of both modalities may provide more diagnostic information in ultrasound doubtful cases.

Key Words: Abnormal placentation - Placenta accreta - MR imaging.

\section{Introduction}

PLACENTA accreta" is a general term for abnormal placentation. Placenta accreta is a lifethreatening condition whose incidence has been rising steadily over the past 50 years. It includes placenta accreta, placenta increta $\&$ placenta percreta [1]

Correspondence to: Dr. Hany M.A. Seif, The Department of Diagnostic Radiology, Faculty of Medicine, Assiut University, Egypt
The prevalence of placenta accreta has increased more than 10 -fold in the past 30 years to approximately 1 in 2500 deliveries [2].

The primary risk factor for placenta accreta is a uterine scar, associated with either a cesarean or a gynecological procedure (such as curettage, myomectomy or hysteroplasty). Placental implantation on the scar area, like anterior placenta previa after previous cesareans, can induce placenta accreta, and the risk increases with the number of previous cesarean sections. Other reported risk factors are maternal age greater than 35 years and multiparity, but the risk of placenta accreta in a healthy uterus is nonetheless very low [3]

Ultrasound is widely used as the initial diagnostic imaging technique during pregnancy because of its availability, portability, and lack of ionizing radiation [4]. Magnetic Resonance (MR) imaging provides superior soft-tissue contrast resolution, multi-planar imaging capabilities, image quality independent of the mother's size or fetus positioning and it lacks ionizing radiation. MRI can be of added diagnostic value when further characterization is required, particularly in the setting of invasive placental processes such as placenta accreta [5]

Aim of work: The purpose of this study was to highlighten the role of Magnetic Resonance Imaging (MRI) in detecting abnormal placentation comparing the results with post-operative and/or histopathological results.

\section{Patients and Methods}

Patients: The study was conducted in the Department of Diagnostic Radiology of Assuit University Hospital. Thirty three females patient (gestational age ranging from 13 to 39 weeks) were referred to MRI Unit with suspected placenta 
accreta in the period between April 2015 and April 2016, their ages were range from 20 to 39 years old. All patients had history of multiple C.S except one and 5 cases were grand multipara with their parity 5 or more. The findings were compared to post-operative findings.

\section{Inclusion criteria:}

- Prenatal diagnosis for:

- Pregnant female patients at second or third trimester with risk factors for abnormal placentation as placenta previa, previous cesarean sections and advanced maternal age.

- Patients who underwent pelvic ultrasound and suspected abnormal placentation.

- Post natal diagnosis for retained placenta.

\section{Exclusion criteria:}

Patients who are contraindicated for MRI examination as those having artificial cardiac pacemaker or metallic prosthesis not compatible with MRI or those with severe claustrophobia, all were excluded from the research.

\section{MRI scan protocol:}

MR studies were conducted with a Philips achieva 1.5-T MR Unit. Urinary bladder during scan was asked to be moderately distended. All the cases were examined in supine position by using the abdomen coil throughout the following sequences: T2-weighted half-fourier technique sagittal, axial and coronal planes perpendicular to the placenta-myometrium interface or myometriumbladder interface and Sagittal T1-weighted imaging. No intravenous injection of gadolinium was used in these cases.

Table (1): Parameters of sequences used in the study.

\begin{tabular}{llll}
\hline & Sag T1 WI & Axial T2 WI & Coronal T2 WI \\
\hline FOV (cm) & 450 X 450 & 450 X 450 & 450 X 450 \\
Sequence type & SE & SE & SE \\
Matrix & 261 X 384 & 288 X 384 & 460 X 512 \\
Flip angle & 150 & 150 & 150 \\
No. of sections & $24-28$ & $24-28$ & $24-28$ \\
Section thickness (mm) & $6-8$ & $6-8$ & $6-8$ \\
Intersection gap (mm) & $0.6-0.8$ & $0.6-0.8$ & $0.6-0.8$ \\
Repetition time msec/echo time msec & $600-700 / 20$ & $4000-5000 / 85$ & $4000 / 40$ \\
Phase-encoding direction & Left to right & anteroposterior & Anteroposterior \\
No. of signals acquired & 3 & 3 & 3 \\
Band width (Hz/pixel) & 190 & 190 & 190 \\
Estimated acquisition time (min) & 4.37 & 4.19 & 3.08 \\
\hline
\end{tabular}

Image analysis:

All patients had undergone the initial sonographic evaluation of the placenta in the Obstetric Department during a routine prenatal examination.

Breath hold Sagittal T2 half fourier images are the first to be evaluated for accurate detection of placental location and its relationship to the internal cervical os, placenta previa was subdivided according to the position of the placenta relative to the internal cervical os into:

1-Low-lying placenta: Placenta is in the lower segment but its edge does not reach the internal os.

2-Marginal placenta: Lower placental edges reach the os but do not cover it.
3- Complete: Edge covers the os and the placenta is asymmetrical.

4- Central: Placenta symmetrically covers the os [6].

Signs of abnormal placentation as placental heterogeneity, dark intra placental bands, focal myometrial interruption and bladder invasion are also evaluated firstly on sagittal images and this signs must be confirmed at least on two different planes. Invasion of the cervix by placental tissue was evaluated also on sagittal view.

Breath-hold coronal $\mathrm{T} 2$ half fourier images were used for detection of focal uterine bulge or loss of normal pear shape of the gravid uterus. 
Sagittal breath-hold T1-weighted image was typically acquired to better show any high-signalintensity sub chorionic hemorrhage, blood clots inside urinary bladder or free intraperitoneal hemorrhage and evaluation of normal fat plane between urinary bladder and uterus which is lost in case of placenta percreta.

\section{Statistical analysis:}

Computer software package SPSS 19 was used in the analysis. For quantitative variables, mean and standard deviation were presented. Sensitivity, specificity; PPV, NPV and accuracy all were calculated for MRI diagnosis of placenta accreta.

\section{Results}

A total number of 33 gravid female, underwent prenatal MRI at gestational age ranged from 1339 weeks gestation.

Their gestational age at the time of examinationranged from 13 to 39 weeks with mean $33.12 \pm$ $6.13(\mathrm{SD})$.

All patients had history of multiple C.S (97\%), except one (3\%).

Among the 33 cases, placenta previa was found to be central in 24 cases $(72.7 \%)$, marginalis in 3 cases $(9.1 \%)$ \& low lying in 6 cases $(18.2 \%)$.

MRI findings: Twenty three patients (69.7\%) had MRI diagnosis of abnormal placentation, 15 cases were diagnosed as placenta accreta and increta (45\%), seven cases diagnosed as placenta percreta $(21.2 \%)$, while ten cases $(30.3 \%)$ were placenta previa without accreta. One case diagnosed as ectopic pregnancy $(3 \%)$ by empty uterine cavity on US and MRI at 13 weeks gestational age where the embryo was implanted on the CS scar with ectopic decidual invasion at the scar site, she had history of previous $1 \mathrm{CS}$.
Intra-operative and histopathological findings: Twenty one cases proved to have placental invasion either intra operative finding and/or by histopathological data, 13 cases $(39.4 \%)$ had placenta accreta and increta, 7 cases $(21.2 \%)$ had placenta percreta $(21.2 \%)$ and one ectopic on CS scar (3\%).

Nineteen cases underwent cesarean hysterectomy following delivery, and two of them had partial cystectomy as well. And one case diagnosed as placenta percreta had post natal angioembolization followed by methotrexate aiming to decrease area of uterine infiltration by placental tissue. Another 2 cases had manual separation of the placenta.

According to the operative findings and/or pathology results, $21(91.3 \%)$ patients were true positive and $2(8.7 \%)$ were false positive (Table 2$)$.

The high sensitivity in our study owing to that all of cases had more than one risk factor for placenta accreta and most of them was suspicious to have abnormal placentation by ultrasonography.

While specificity in our study was $83.3 \%$ due presence of two false positive cases. This 2 cases were in high risk patients, MRI showed low signal area interpreted as dark T2 bands and data during surgery, the placenta separated spontaneously and no accreta was detected.

In our study, the sensitivity of MRI features of patients proved to be accreta are focal interruption in the myometrial wall in 23 cases $(100 \%)$, dark intraplacental bands in 22 cases $(95.6 \%)$, heterogeneous placental signal intensity was found in 15 cases $(65.2 \%)$, focal myometrial interruption in 23 cases $(100 \%)$, uterine bulging 12 cases $(52.1 \%) \&$ direct visualization of invasion of pelvic structures in 5 cases $(21 \%)$ (Table 3$)$.

Table (2): MRI sensitivity and specificity in diagnoses of placenta accreta.

\begin{tabular}{lcccccc}
\hline Sensitivity & Specificity & $+\mathrm{PV}$ & $-\mathrm{PV}$ & Accuracy & AUC & $95 \% \mathrm{CI}$ \\
\hline 100.00 & 83.33 & 91.3 & 100.0 & 93.94 & 0.917 & $0.767-0.984$ \\
\hline
\end{tabular}

Table (3): Sensitivity, specificity, PPV and NPV of MRI diagnostic criteria for placenta accreta.

\begin{tabular}{lccccc}
\hline & Sensitivity & Specificity & $(+)$ ve PV & $(-)$ ve PV & Accuracy \\
\hline Uterine bulging & 57.14 & 100.00 & 100.00 & 57.1 & 72.72 \\
Heterogeneous placenta intensity & 71.43 & 91.67 & 93.7 & 64.7 & 78.79 \\
Dark intraplacental bands on T2 & 95.24 & 66.67 & 83.8 & 88.9 & 84.85 \\
Focal interruption in myometrial wall & 100.00 & 50.00 & 77.8 & 100.0 & 81.82 \\
Direct visualization of invasion of pelvic structures & 71.43 & 100.00 & 100.00 & 92.9 & 93.94 \\
Thick intraplacental bands + focal myometrial interruption & 95.24 & 83.33 & 90.9 & 90.9 & 90.9 \\
\hline
\end{tabular}


In our study, uterine bulging and direct visualization of the pelvic structures were found to have the highest specificity $(100 \%)$ followed by heterogeneous placental intensity $(91.67 \%)$ (Table 3$)$.

Case (1):
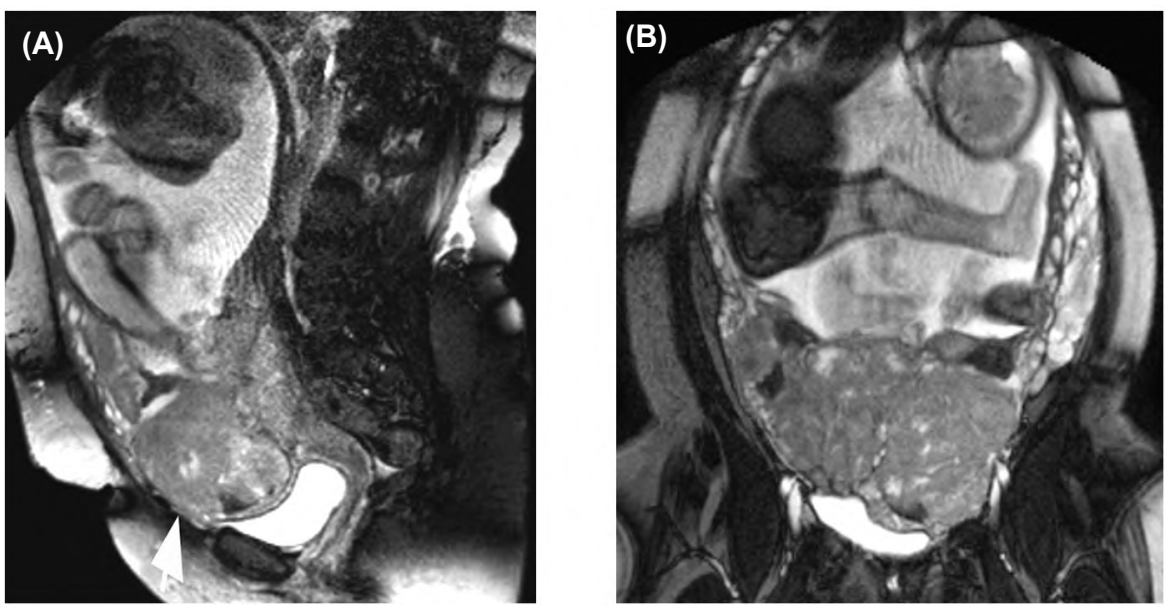

Fig. (1): Pregnant female patient, 33 years old, gestational age 36 weeks, previous history of 3 CS, sagittal A and coronal B T2 HASTE MR images showing central placenta previa with dark intraplacental bands and focal myometrium interruption at the lower segment anteriorly (white arrow) and focal uterine bulge.

Case (2):
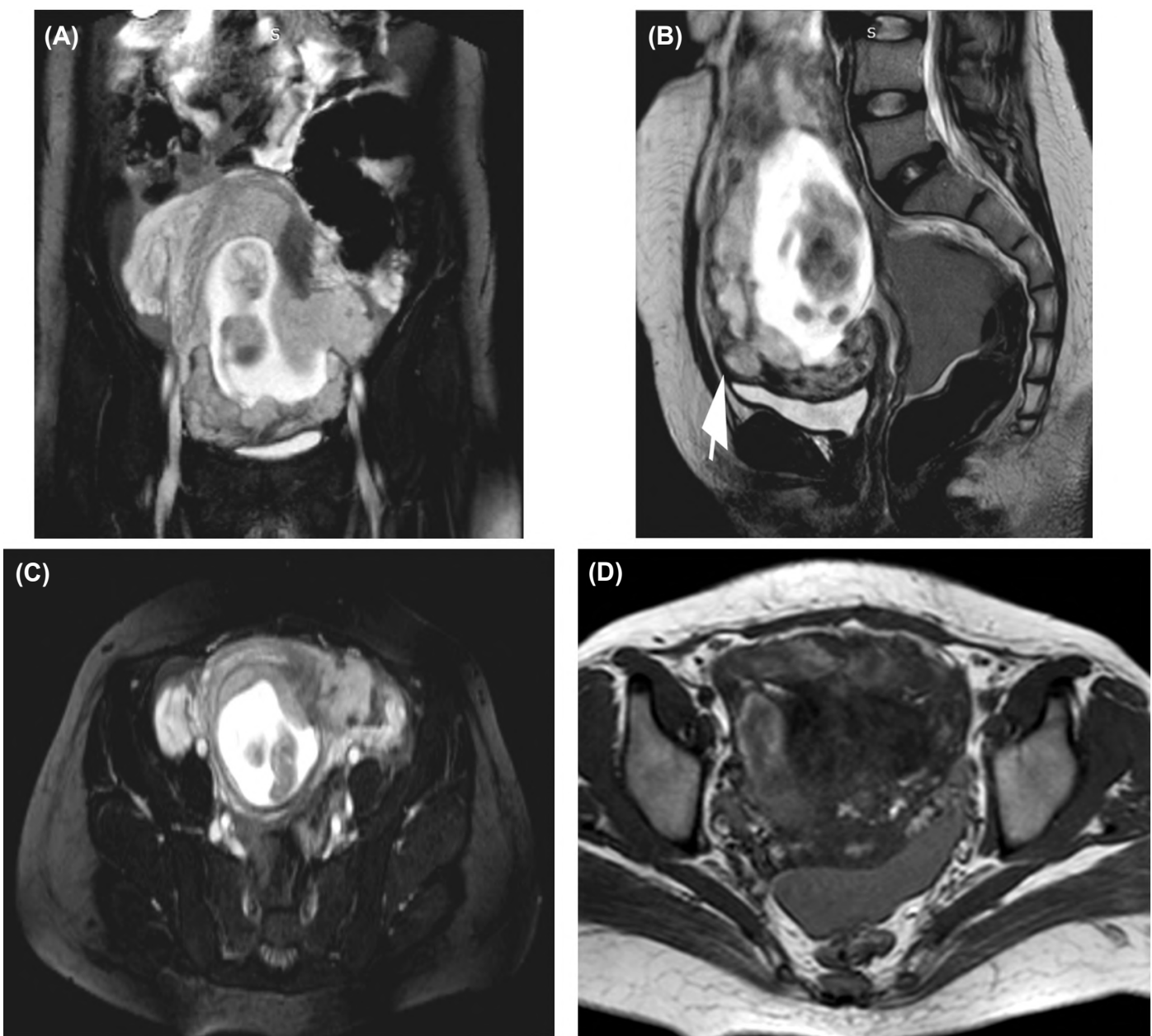

Fig. (2): Pregnant female patient, 25 years old, gestational age 17 weeks, with history of previous 1 C.S. Coronal A, Sagittal B and axial C T2 HASTE MRI showing marginal placenta previa with invasion of myomterial wall at the site of previous SC scar (white arrow) and also there is free collection at Doglous pouch, the axial images showing placental tissue protruding outside myometrial wall with suspicious of invasion of the near by vessels. Axial T1WI showing hyper intense signal of free intraperitoneal fluid collection denoting that its bloody collection. 
Case (3):
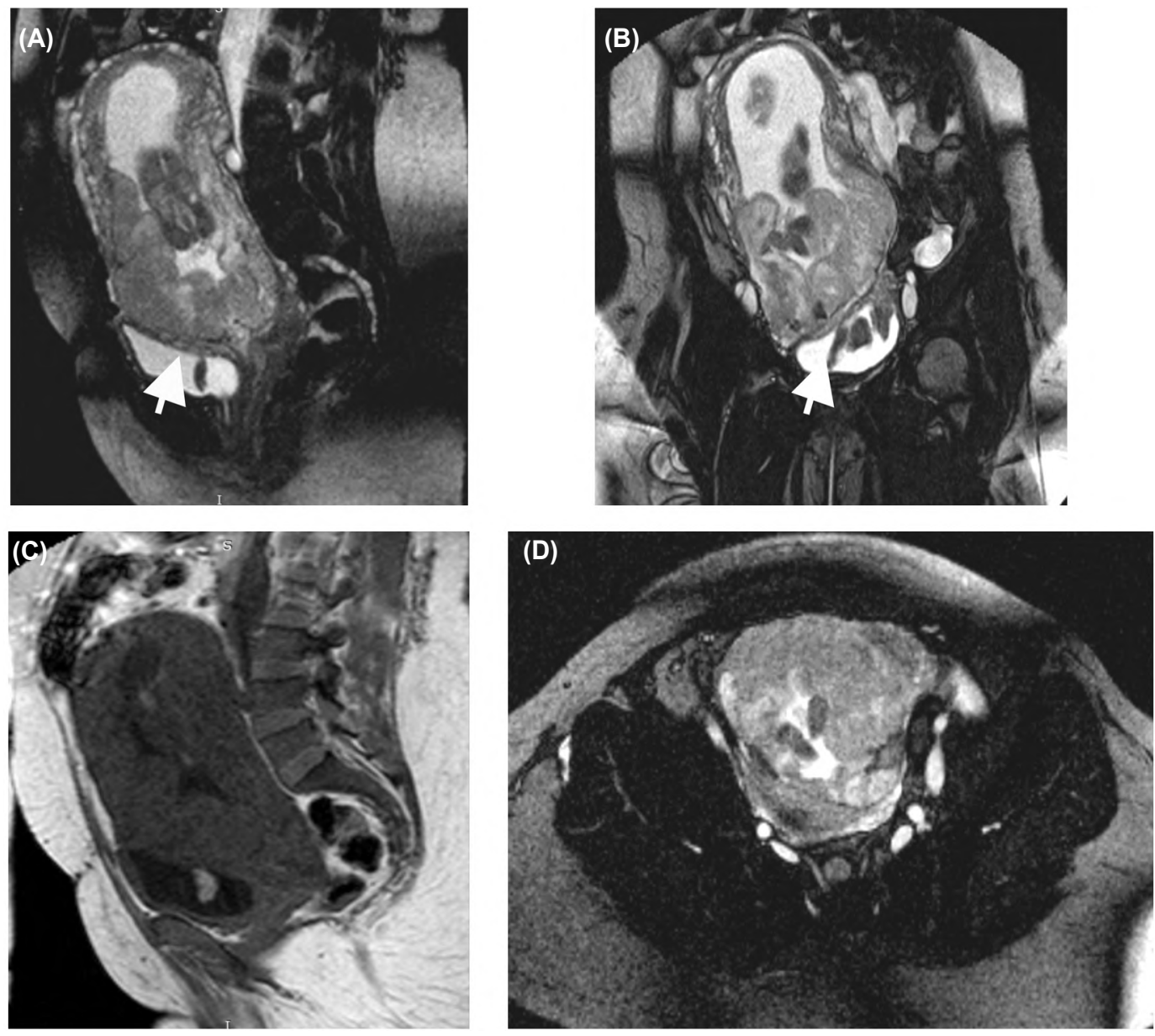

Fig. (3): Pregnant female patient 30 years old, gestational age 19 weeks came to the Obstetric Department by hematuria with history of previous 4 C.S Sagittal A, coronal B and axial D T2 HASTE MRI showing central placenta previa with bladder invasion at its dom (white arrow) with blood clots inside and dark intraplacental bands. Sagittal C T1 WI showing obliteration of fat plane between bladder uterine interface.

Case (4):

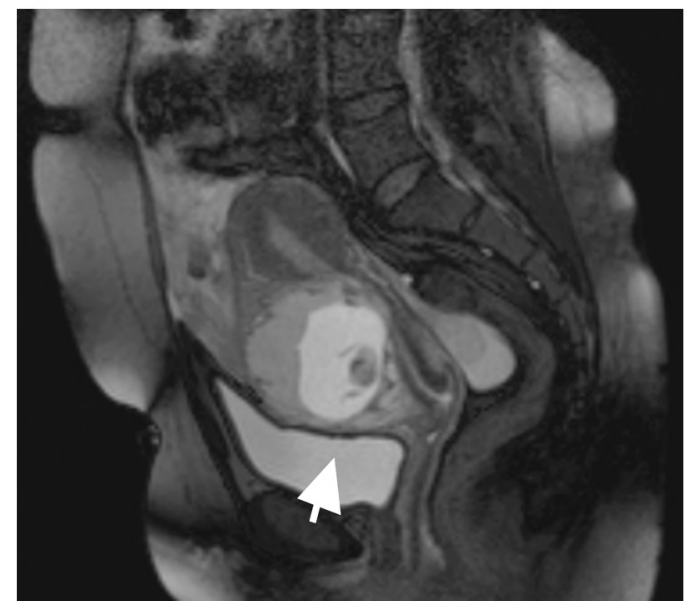

Fig. (4): Pregnant female patient, 30 years old, gestational age 13 weeks with history of previous 1 C.S. Sagittal T2 HASTE showing gestational sac ectopic on the previous CS scar with empty endometrial cavity (white arrow).

\section{Discussion}

Imaging of the placenta can have a profound impact on patient management, owing to the morbidity and mortality associated with various placental conditions [7]

The greatest risk for placenta accreta is previous cesarean delivery and the presence of placenta previa. The risk of placenta accreta is $24 \%$ in women with placenta previa and one prior cesarean delivery and $67 \%$ in women with placenta previa and three or more prior cesarean deliveries. Other risk factors include increasing maternal age and a history of uterine surgery [8]. The surgical history of a patient is therefore extremely valuable in identifying women at highest risk for accreta [9], in our study we found that combination between prior CS and placenta previa increase the incidence of placenta accreta rather than the other risk factors. 
Placenta accreta is a potential life-threatening obstetric condition that requires a multidisciplinary approach to management. Diagnosis of placenta accreta before delivery allows multidisciplinary planning in an attempt to minimize potential maternal or neonatal morbidity and mortality [10].

Ultrasonography and Magnetic Resonance Imaging (MRI) are the modalities for prenatal diagnosis of abnormal placentation, although Ultrasonography remains the primary investigation of choice (as it is relatively inexpensive and easily available) [11].

However, some authors have pointed out that US might be limited in the extent to which it can assess depth of invasion in women with suspected placenta accreta. Others asserted that US lacks the necessary resolution to identify accreta in posterior placenta or the patients body habitus presents a barrier through the scan [9].

MRI can be of added diagnostic value when further characterization is required, particularly in the setting of invasive placental processes such as placenta accreta. Some authors have suggested that MR imaging is most clearly indicated when there is a posterior placenta or when the US findings are ambiguous. Others have suggested that MR imaging can better define areas of abnormal placentation, modify levels of invasion, and ultimately change surgical management and should be used routinely [5]

Our study shows sensitivity and specificity of MR imaging of $100 \%$ \& $83.3 \%$ respectively in its ability to diagnose placental invasion this matches the results of previously publicated data of Warshak, et al., [2], Mansour, et al., [12] and Dwyer, et al., [13] that show overall sensitivity and specificity of MR imaging have been given as $80 \%-88 \%, 93.3 \%$ $85 \%$ and $80 \%-65 \%$ respectively.

In our study all cases of placental invasion had previous CS and the number of previous CS was not correlated with the degree of invasion.

The high sensitivity of MRI in our study could be explained by presence of more than one risk factors in our patients and most of them were suspicious for placenta accreta by Ultrasonography, also using spin echo sequences with controlled breath hold as in Mansour, et al., [12] study. Such an option provided images of better resolution and almost nil motion artifacts from fetal body motion and maternal bowel peristalsis and respiration, also we relied upon different sequences (breath hold T2WI FSE and T1WI SE) in different orientations (axial, coronal and sagittal) in evaluating the study cases.

In our study, we found that presence of focal uterine bulge, the abnormal heterogeneous signal intensity of the placenta and dark intraplacental bands were have the most specific criteria with $100 \%, 91.6 \%$ and $66.6 \%$ specificity, respectively for diagnosis of abnormal placentation. The most accurate finding in diagnosis of invasive placenta were combination between dark intraplacental bands and focal inner myometrium interruption with sensitivity $95.2 \%$, specificity $83.3 \%$ and $90.9 \%$ accuracy. Direct invasion of pelvic structure was found to be the most specific criteria for placenta percreta with accuracy $93.9 \%$. Our results were in agreement of Lax et al., [14] results who described the three signs of abnormal placentation on MRI: Irregular thick intraplacental T2 dark bands, marked placental heterogeneity, and bulging of the lower uterine segment. Homogeneous placentas were overwhelmingly benign, and markedly heterogeneous placentas with T2 dark bands were associated with invasive placentation. Lax, et al., postulated that the abnormal $\mathrm{T} 2$ dark bands were the result of fibrin deposition.

In contrast with Laurance, et al., [15] who found that placental heterogeneity was not significantly associated with the diagnosis of invasive placenta. It is currently admitted that normal placenta shows some degree of physiological heterogeneity. In this regard Blaicher, et al., [16] described the spectrum of normal presentation of the placenta. They found placental heterogeneity in a number of cases with variations depending on the gestational age.

While Varghese, et al., [17] said that the dark intraplacental bands are also seen in placental infarction and intervillous thrombus and described this as a common pitfall in the diagnosis of PA.

Our results were in disagreement with Derman, et al., [8] results who described early MR criteria for the diagnosis of placenta accreta primarily focused on identification of direct invasion of the placenta into the uterus as defined by thinning, indistinctness of the myometrium, and loss of the thin T2 dark uteroplacental interface and on direct visualization of placental tissue within or outside the myometrium. These MR criteria were found to be nonspecific because the myometrium becomes very thin, especially in the region of the cesarean scar, during the third trimester of pregnancy and is difficult to adequately visualize on MRI. Furthermore the focal absence of the dark uteroplacental interface on T2 HASTE images can be found 
in normal placentas and is not a sensitive criterion when considered in isolation [8] .

\section{Conclusion:}

Magnetic resonance imaging hand in hand with ultrasound is important for the accurate diagnosis of abnormal placentation. Co-operation of both modalities may provide more diagnostic information. Inclusion of MR imaging in the routine evaluation of patients with high risk for abnormal placentation may reduce hospital stays and unnecessary interventions with favorable outcome.

\section{References}

1- PRIDJIAN G., HIBBARD J.U., MOAWAD A.H.: Cesarean: Changing the trends. Obstet. Gynecol., 77: 195-200, 1991.

2- WARSHAK C.R., ESKANDER R., HULL A.D., et al.: Accuracy of ultrasonography and magnetic resonance imaging in the diagnosis of placenta accreta. Obstet. Gynecol., 108: 573-81, 2006.

3- MILLER D.A., CHOLLET J.A. and GOODWIN T.M.: Clinical risk factors for placenta previa placenta accreta. Am. J. Obstet. Gynecol., 177: 210-4, 1997.

4- ELSAYES K.M., TROUT A.T., FRIEDKIN A.M., et al.: Imaging of the Placenta: A Multimodality Pictorial Review. Radiographics, 29: 1371-91, 2009.

5- MASSELLI G., BRUNELLI R., CASCIANI E., et al.: Acute abdominal and pelvic pain in pregnancy: $M R$ imaging as a valuable adjunct to ultrasound? Abdominal Imaging, 36 (5): 596-603, 2011.

6- AIKEN C.E.M., MEHASSEB M.K. and KONJE J.C.: Placent alabnormalities. In Arulkumaran SS, Karoshi M, Keith LG, Lalonde AB, B-Lynch C (eds.) A Comprehensive Textbook of Postpartum Hemorrhage. ${ }^{\text {nd }}$ ed. Sapiens Publishing, 27: 227-39, 2012.

7- MASSELLI G., GIANFRANCO GUALDI, et al.: MR imaging of the placenta: What a radiologist should know,
Abdominal imaging, 2013, Volume 38, Issue 3, pp. 573 587 To WW, Leung WC Placenta previa and previous cesarean section. Int. J. Gynaecol. Obstet., 51 (1): 25-31, 1995.

8- DERMAN A.Y., NIKAC V., HABERMAN S., et al.: MRI of Placenta Accreta: A New Imaging Perspective. A.J.R., 197: 1514-21, 2011.

9- LAM G., KULLER J. and McMAHON M.: Use of magnetic resonance imaging and ultrasound in the antenatal diagnosis of placenta accreta. J. Soc. Gynecol. Invest., 9: 37-40, 2002.

10- Committee Opinion No. 529. American College of Obstetricians and Gynecologists. Placenta accreta. Obstet. Gynecol., 120: 207-11, 2012.

11- MOHAMMAD A. YOUSIF EL-SHAZLY: Role of MRI in diagnosis of placenta accreta. J. Am. Sci., 10 (6): 119 124]. (ISSN: 1545-1003), 2014.

12-MANSOUR S.M. and ELKHAYAT W.M.: Placenta previaaccreta. Do we need MR imaging? The Egyptian Journal of Radiology and Nuclear Medicine, 42: 433-43, 2011.

13- DWYER B.K., BELOGOLOVKIN V., TRAN L., RAO A., CARROLL I., BARTH R., et al.: Prenatal diagnosis of placenta accreta: Sonography or magnetic resonance imaging? J. Ultrasound. Med., 27: 12751281, 2008.

14- LAX A., PRINCE M.R., MENNITT K.W., et al.: The value of specifi c MRI features in the evaluation of suspected placental invasion. Magn. Reson. Imaging, 25: 87-93, 2007.

15- LAURENCE BOUR, VINCIANE PLACÉ, SANDRA BENDAVID, YANN FARGEAUDOU, JEAN-JACQUES PORTAL, AUDE RICBOURG, et al.: Suspected invasive placenta: Evaluation with magnetic resonance imaging, Eur. Radiol., 24: 3150-60, 2014.

16- BLAICHER W., BRUGGER P.C., MITTERMAYER C., et al.: Magnetic resonance imaging of the normal placenta. European Journal of Radiology, 57: 256-60, 2006.

17- VARGHESE B., SINGH N., GEORGE R.A. and GILVAZ S.: Magnetic resonance imaging of the placenta accreta. Indian J. Radiol. Imaging, 23: 379-85, 2013. 


\section{دور الرنين المغناطيسى إلمشئ \\ فى تشخيص إلتصاقات المشيميمة المغيسة}

المشيمة هى الجهاز الذى ينمو فى الرحم آثناء الحمل. حياة الجنين تعتمد على حيوية المشيمة وحياة المشيمة تعتمد على صحة الآم التى التى

تلتصق بها بشكل وثيق جدا . وبالتالى هذا الثالوث من الآم-المشيمة-الجنين يصبح مهم جدا في عملية تطو الجنين الطفل والولادة باكملها.

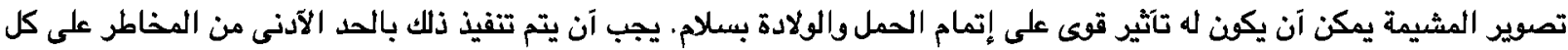

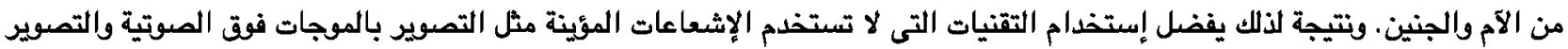

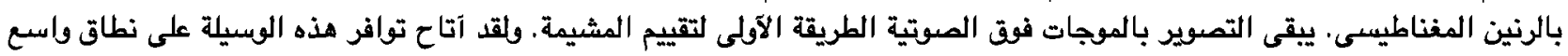

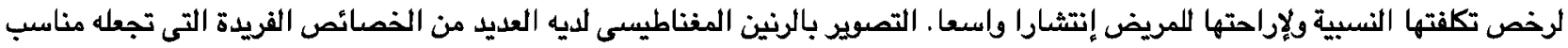

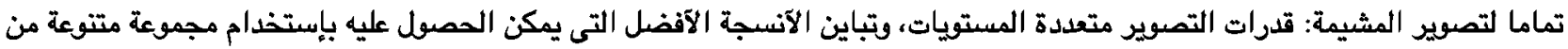
تسلسل النبض والمعلمات وعلم وجود الإشعاع المؤين.

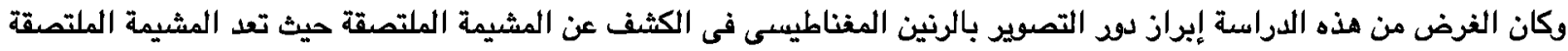

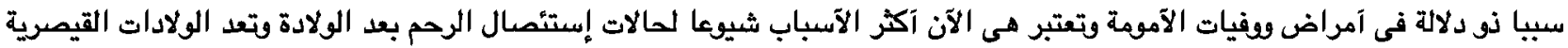

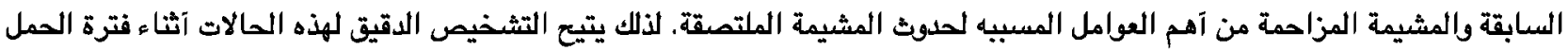
فرص آفضل لمناجزة الولادة.

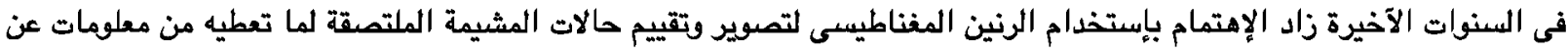

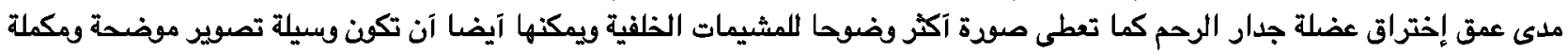

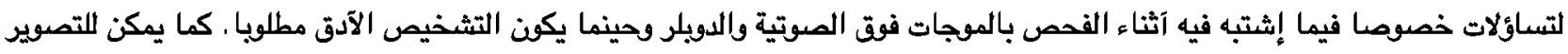

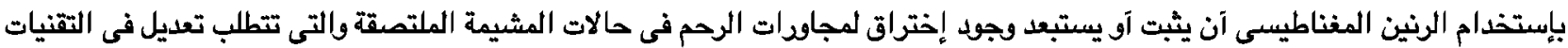

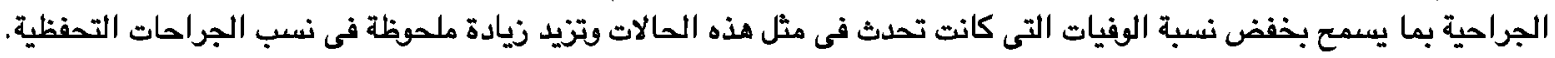

شملت هذه الدراسة ثلاثة وثلاثون سيدة حامل اللاتى لديهن آكثر من عامل يسبب المشيمة الملتصقة مثل المشيمة المزاحة آو الولادات

القيصرية السابقة.

ونخرج من هذا البحث بالتوصيات الآتية:

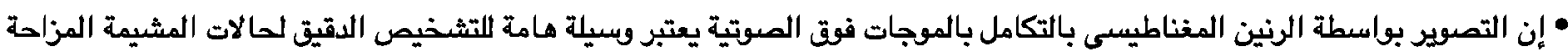
وتلازمها مع حالات المشيمة الملتصقة. التعاون بين الوسيلتين يمكنتا من معرفة المزيد من المعلومات التشخيصية.

• إستخدام التصوير بالرنين المغناطيسى كوسيلة إعتيادية فى تقييم حالات مرضى المشيمة المزاحة يمكن آن ئدئى إلى تقليل فترة الإقامة بالمستشفى وتقليص التدخلات الغير ضرويرية بما يعطى نتائج أُفضل. 